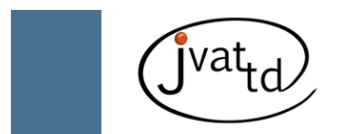

\title{
Characterization of Clostridium perfringens isolated from mammals and birds from Guwahati city, India
}

Rahman Mafruza S (1), Sharma RK (1), Borah P (1), Chakraborty A (1), Devi Mandakini RK (1), Longjam N (1)

(1) Department of Microbiology, College of Veterinary Science, Assam Agricultural University, Khanapara, Guwahati, Assam, India.

\begin{abstract}
Of the 102 samples collected from mammals and birds, both domestic and captive wild, 48 were found to be positive for Clostridium perfringens. Most of the mammal isolates (84.38\%) appeared to have been collected from clinically affected animals, while $33.33 \%$ of the bird samples were from clinically affected and $21.43 \%$ from apparently healthy birds infected with C. perfringens. Isolates revealed high sensitivity to ciprofloxacin, enrofloxacin and norfloxacin. Among the isolated C. perfringens, 30 (62.50\%) showed DNase production. Hemolytic activity was recorded in 14 (24.16\%) of the isolates and 28 (58.33\%) showed phospholipase $C$ production. All the phospholipase $C$ positive isolates revealed the presence of cpa gene encoding alpha $(\alpha)$ toxin. Of the 102 samples collected from mammals and birds, both domestic and captive wild, 48 were found to be positive for Clostridium perfringens. Most of the mammal isolates (84.38\%) appeared to have been collected from clinically affected animals, while $33.33 \%$ of the bird samples were from clinically affected and $21.43 \%$ from apparently healthy birds infected with C. perfringens. Isolates revealed high sensitivity to ciprofloxacin, enrofloxacin and norfloxacin. Among the isolated C. perfringens, $30(62.50 \%)$ showed DNase production. Hemolytic activity was recorded in 14 (24.16\%) of the isolates and 28 (58.33\%) showed phospholipase C production. All the phospholipase C positive isolates revealed the presence of cpa gene encoding $\alpha$ toxin.
\end{abstract}

Key words: Clostridium perfringens, PCR, $\alpha$ toxin, cpa gene, polymerase chain reaction.

\section{INTRODUCTION}

Different cases of acute enteritis or fatal enterotoxemia have been reported in several animal species. Sudden death in bovines, ovines and caprines have also been attributed to Clostridium perfringens that produce a number of exotoxins and enzymes, which, in turn, have important roles in the production of various disease manifestations like severe gangrene, diarrhea, dysentery, muscle infection and various forms of enteric diseases. The organism is transmitted directly from infected to healthy animals through contaminated soil, animal feed and litter (1).
The toxins produced depend on the $C$. perfringens strain involved and each type induces a specific syndrome. Therefore, a correct identification of pathovars is critical for epidemiological study. As the diseases caused by this organism are soil-borne, effective vaccination rather than management practices can control the disease. Before vaccination, detailed characterization of the causative agent isolated from diverse sources is of paramount importance.

\section{MATERIALS AND METHODS}

Fecal materials, affected muscletissues, intestinal contents and internal organs were collected from 
apparently healthy, clinically affected and dead mammals and birds with suspicion of clostridial infection. The study included both domestic and captive wild mammals and birds, in and around Guwahati city in Assam state, India, including the Assam State Zoo.

\section{Isolation and Identification of $\boldsymbol{C}$. perfringens}

Clinical materials were inoculated deep into the Robertson's cooked meat broth (RCMB) medium as per the standard method and incubated under anaerobic condition at $37^{\circ} \mathrm{C}$ for 48 hours (2). Broth cultures exhibiting typical growth characteristics of $C$. perfringens, i.e. production of acid and gas without digestion of meat, sour odor of the culture and reddening of meat were further sub-cultivated on $5 \%$ sheep blood agar plates and incubated at $37^{\circ} \mathrm{C}$ for 24 hours under anaerobic conditions for proliferation. Isolates were at first identified as $C$. perfringens on the basis of cultural, morphological and biochemical characteristics (2).

\section{Susceptibility to Antimicrobial Agents}

C. perfringens isolates presenting in vitro susceptibility to 12 different antimicrobial agents were tested by a disc diffusion method (3).

\section{Characterization of $C$. perfringens Isolates}

All the isolates recovered in the present study were characterized with respect to their DNase, hemolysin and phospholipase production.

\section{Detection of Deoxyribonuclease (DNase) Production by C. perfringens Isolates}

Isolates were tested for DNase production according to the standard method (4).

\section{Detection of Hemolysin Production by $C$. perfringens Isolates}

Hemolysin produced by the $C$. perfringens isolates was detected by inoculating the bacterial colonies on sheep blood agar, as previously described (1). Inoculated plates were incubated at $37^{\circ} \mathrm{C}$ anaerobically for 24 hours. Presence of hemolytic zones (double or single) around colonies indicated production of hemolysin.

\section{Detection of Phospholipase C (Nagler's Reaction)}

The production of phospholipase $\mathrm{C}$ by the C. perfringens isolates was verified according to the literature (5). Suspected colonies were inoculated into Wills and Hobb's medium without lecithinase-specific antisera, and added to neomycin sulfate at the concentration of 250 $\mu \mathrm{g}$ per $\mathrm{mL}$. Plates were incubated anaerobically at $37^{\circ} \mathrm{C}$ for 24 hours and then examined for the presence of a pink zone of opacity around the lecithinase-positive and lactose-positive colonies.

\section{Polymerase Chain Reaction (PCR) - Detection of cpa Gene}

The cpa gene that encodes for $\alpha$ toxin in the C. perfringens isolates was detected by PCR (6). Two to five colonies from each isolate grown on blood agar were suspended separately into $100 \mu \mathrm{L}$ of Milli Q water in a $1.5 \mathrm{~mL}$. The reaction was contained in an Eppendorf tube.

Specific primers $\quad$ cpa IFP 5GCTAATGTTACTGCCGTTGA-3' and $c p a$ IPR 5'CCTCTGATACATCGTGTAAG $-3^{\prime}$ ) as previously described were used for the detection of the cpa gene (324 bp) (6). The PCR reaction was performed in a thermocycler (BioRad, USA). Amplified bands were visualized by gel documentation.

\section{RESULTS}

On bacteriological examination, 48 (47.06\%) of the 102 samples revealed the presence of C. perfringens, including 44 (51.76\%) from domestic and captive wild mammals, and 4 $(23.53 \%)$ from birds (Table 1). Frequency of isolation was found to be higher (84.38\%) from clinically affected compared to apparently healthy (32.08\%) animals. Similarly, 33.33 and $21.43 \%$ of the clinically affected and apparently healthy birds, respectively, were found to be positive for C. perfringens. C. perfringens isolates showed highest sensitivity to ciprofloxacin followed by enrofloxacin and norfloxacin.

Among the C. perfringens isolates, 30 (62.50\%) were found to be positive for DNase production. Of these, 29 were from mammals and one from a bird. The majority of the isolates positive for DNase production were from clinically affected birds and mammals. Hemolysin production could be detected in 14 (29.16\%), including 13 of nonavian origin (Table 1). From these, ten were from clinically affected mammals, as was the bird isolate (Table 1). A total of 28 (58.33\%) isolates were positive for phospholipase $\mathrm{C}$ production and all 
Table 1. Prevalence and characterization of Clostridium perfringens of mammal and bird origin in relation to deoxyribonuclease (DNase), hemolysin, phospholipase C production and presence of $c p a$ gene in Guwahati city during 2009 and 2010

\begin{tabular}{|c|c|c|c|c|c|c|}
\hline \multirow{2}{*}{$\begin{array}{l}\text { Sample } \\
\text { source }\end{array}$} & \multirow{2}{*}{$\begin{array}{l}\text { Examined } \\
\text { samples }\end{array}$} & \multirow{2}{*}{$\begin{array}{l}\text { C. perfringens } \\
\text { presence }\end{array}$} & \multicolumn{4}{|c|}{ Isolates showing production/presence of } \\
\hline & & & cpa gene & DNase & Hemolysin & Phospholipase C \\
\hline \multicolumn{7}{|c|}{ A. Mammals (apparently healthy) } \\
\hline Bovine & 10 & 1 & 1 & 0 & 1 & 0 \\
\hline Goat & 10 & 2 & 2 & 2 & 2 & 0 \\
\hline Sheep & 2 & 2 & 2 & 0 & 0 & 0 \\
\hline Elephant & 9 & 5 & 5 & 3 & 0 & 0 \\
\hline Tiger & 2 & 1 & 1 & 0 & 0 & 0 \\
\hline Lion & 2 & 0 & 0 & 0 & 0 & 0 \\
\hline $\begin{array}{c}\text { Pig-tailed } \\
\text { monkey }\end{array}$ & 1 & 0 & 0 & 0 & 0 & 0 \\
\hline $\begin{array}{l}\text { Stump-tailed } \\
\text { monkey }\end{array}$ & 5 & 1 & 1 & 0 & 0 & 0 \\
\hline $\begin{array}{l}\text { Bonnet } \\
\text { monkey }\end{array}$ & 1 & 1 & 1 & 0 & 0 & 0 \\
\hline $\begin{array}{l}\text { Lion-tailed } \\
\text { monkey }\end{array}$ & 1 & 1 & 1 & 0 & 0 & 0 \\
\hline $\begin{array}{l}\text { Golden } \\
\text { langur }\end{array}$ & 3 & 1 & 1 & 1 & 0 & 0 \\
\hline Sambar & 2 & 1 & 1 & 0 & 0 & 0 \\
\hline Hog deer & 4 & 0 & 0 & 0 & 0 & 0 \\
\hline Serow & 1 & 1 & 1 & 1 & 0 & 0 \\
\hline Total (\%) & 53 & $17(32.08)$ & 17 & 7 & 3 & 0 \\
\hline \multicolumn{7}{|c|}{ B. Mammals (clinically affected) } \\
\hline Cattle & 5 & 4 & 4 & 4 & 0 & 4 \\
\hline Pigmy hog & 2 & 2 & 2 & 2 & 1 & 2 \\
\hline Goat & 14 & 12 & 12 & 12 & 5 & 12 \\
\hline Sheep & 3 & 3 & 3 & 0 & 2 & 3 \\
\hline Dog & 2 & 2 & 2 & 2 & 0 & 2 \\
\hline Elephant & 6 & 4 & 4 & 2 & 2 & 4 \\
\hline Total (\%) & 32 & $27(84.38)$ & 27 & 22 & 10 & 27 \\
\hline \multicolumn{7}{|c|}{ C. Birds (apparently healthy) } \\
\hline Macaw & 1 & 1 & 1 & 0 & 0 & 0 \\
\hline Cassowary & 2 & 1 & 1 & 0 & 0 & 0 \\
\hline Peacock & 1 & 1 & 1 & 0 & 0 & 0 \\
\hline Chicken & 10 & 0 & 0 & 0 & 0 & 0 \\
\hline Total (\%) & 14 & $3(21.43)$ & 3 & 0 & 0 & 0 \\
\hline \multicolumn{7}{|c|}{ C. Birds (clinically affected) } \\
\hline Pigeon & 3 & 1 & 1 & 1 & 1 & 1 \\
\hline Total (\%) & 3 & $1(33.33)$ & 1 & 1 & 1 & 1 \\
\hline $\begin{array}{c}\text { Grand Total } \\
(\%)\end{array}$ & 102 & $48(47.06)$ & 48 & $30(62.50)$ & $14(29.16)$ & $28(58.33)$ \\
\hline
\end{tabular}




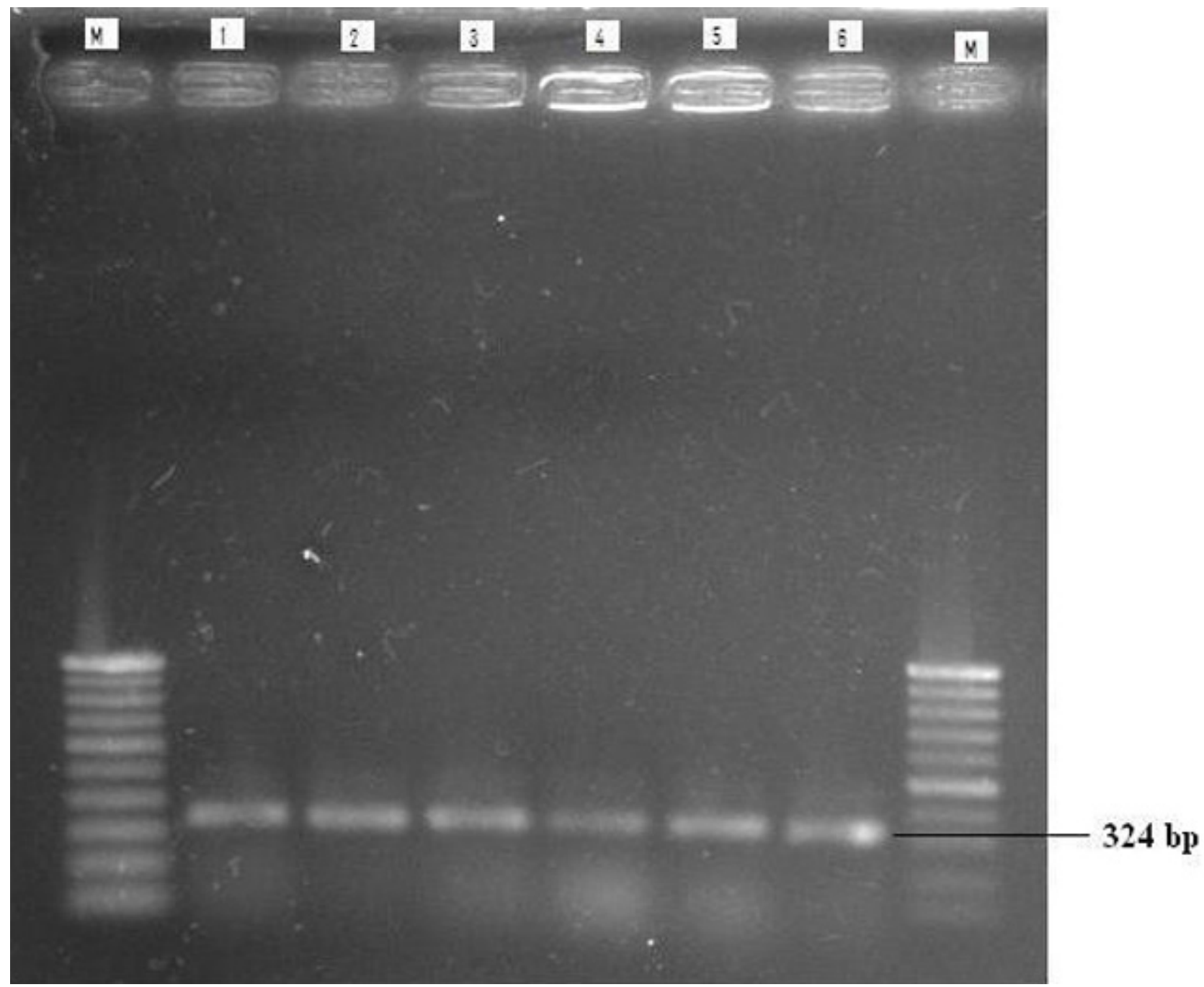

Figure 1. Detection of $\alpha$ toxin (cpa) gene in C. perfringens by PCR. Lane M: 100 bp molecular marker; lanes 1 to 5: $C$. perfringens field isolates; lane 6 : known strain of $C$. perfringes bearing a toxin gene.

were recovered from clinically affected birds and other animals (Table 1). All the 48 C. perfringens isolates revealed presence of $\alpha$ toxin gene (Figure 1). All the C. perfringens samples presenting the $\alpha$ toxin gene isolated from clinically affected birds and mammals also exhibited phospholipase C activity.

\section{DISCUSSION}

Clostridium perfringens is ubiquitous in nature and usually forms a part of the normal intestinal flora of humans and animals. Spores of the organism persist in the soil, sediments and areas subjected to human or animal fecal pollution (7). In its role in the intestinal flora, C. perfringens becomes associated with various forms of disease under certain favorable conditions. Therefore, detection of virulence factors including identification of toxin genes in the isolates of $C$. perfringens plays a significant role in the differentiation of pathogenic from non-pathogenic organisms and in establishing its role in the disease condition.

PCR-based technology is considered to be a convenient and highly reliable tool for molecular detection of all the major toxin genes, such as $\alpha$ (cpa), $\beta$ (cpb1), $\varepsilon$ (etx) and I (iap) (8). The $\alpha$ toxin is considered to be one of the major toxins produced by all different types of $C$. perfringens. Given the importance of this organism, it is imperative to characterize the isolates in terms of their virulence factors to establish their pathogenic potential and to detect genes encoding major toxins. 
Isolation of $C$. perfringens from both apparently healthy as well as clinically affected birds and mammals confirmed the ubiquitous nature of the organism reported in another work (9). The higher sensitivity of the isolates to ciprofloxacin, enrofloxacin and norfloxacin may be due to infrequent use of these drugs in birds and mammals under study for therapeutic and prophylactic purposes.

Characterization of virulence properties indicated production of DNase by the majority of the isolates, most of which were recovered from clinically affected birds and mammals. This indicates that DNase presence is an important virulence factor in disease production. This observation agrees with previous findings, which reported DNase production in all strains of $C$. perfringens isolated from cases of atypical blackleg in cattle (10).

The high presence of hemolysin in the isolates was also reported in all the strains of $C$. perfringens type $\mathrm{C}$ isolated from cases of enterotoxemia in domestic animals (11). All isolates of $C$. perfringens positive for phospholipase $C$ production presented the $\alpha$ toxin gene, which is indicative of $C$. perfringens type A involvement in the disease of clinically affected animals (12).

From the data of the present study, the distribution of $C$. perfringens toxin types could not be ascertained in relation to animals or disease conditions. Additional studies must be carried out with specific primers to detect other major toxins in the isolates to determine the real prevalence of $C$. perfringens types in birds and mammals.

However, the predominance of $\alpha$ toxin in the strains isolated from clinically affected animals suggests the importance of this agent in producing disease in birds and mammals.

\section{COPYRIGHT}

\section{(C) CEVAP 2012}

\section{SUBMISSION STATUS}

Received: June 29, 2011.

Accepted: October 3, 2011.

Abstract published online: October 6, 2011.

Full paper published online: February 28, 2012.

\section{CONFLICTS OF INTEREST}

The authors declare no conflicts of interest.

\section{ETHICS COMMITTEE APPROVAL}

The present study was approved by the institutional review board of the Department of Microbiology, College of Veterinary Science, Assam Agricultural University, Khanapara, India.

\section{CORRESPONDENCE TO}

R. K. Sharma, Department of Microbiology, College of Veterinary Science, Assam Agricultural University, Khanapara, Guwahati-22, Assam, India. Phone: +91-94350 64887. Fax: 03612847195. Email: dr.sharmark@rediffmail.com.

\section{REFERENCES}

1. McGinley S. Clostridium perfringens: New ways to type strains of a deadly bacteria. Arizona: Arizona Experiment Station Research Report; 1998. Available from: http://ag.arizona.edu/pubs/general/resrpt1998/ clostridium.html.

2. Cruickshank R, Duguid JP, Marmion BP, Swain RHA, editors. Medical microbiology. $12^{\text {th }}$ ed. Edinburgh, London: Churchill Livingstone; 1975. 522-35 p. II vol.

3. Wust J. Susceptibility of anaerobic bacteria to metronidazole, ornidazole and tinidazole, and routine susceptibility testing by standardized methods Antimicrob Agents Chemother. 1977;11(4):631-7.

4. Porschen RK, Sonntag S. Extracellular deoxyribonuclease production by anaerobic bacteria. Appl Microbiol. 1974;27(6):1031-3.

5. Baldassi L, Barbosa ML, Bach EE, Iaria ST. Toxigenicity characterization of Clostridium perfringens from bovine isolates. J Venom Anim Toxins incl Trop Dis. 2002;8(2):112-26.

6. Titball RW, Hunter SE, Martin KL, Morris BC, Shuttleworth AD, Rubidge $\mathrm{T}$, et al. Molecular cloning and nucleotide sequence of the alpha-toxin (phospholipase C) of Clostridium perfringens. Infect Immun. 1989;57(2):367-76.

7. Taylor AW, Gordon WS. A survey of the types of $C$. welchii present in soil and the intestinal contents of animals and man. J Pathol Bacteriol. 1940;50(1):271-7.

8. Yoo HS, Lee SU, Park KY, Park YH. Molecular typing and epidemiological survey of prevalence of Clostridium perfringens types by multiplex PCR. J Clin Microbiol. 1997;35(1):228-32.

9. Harbola PC, Arora BM. Enterotoxaemia due to Clostridium perfringens type D in sloth bear. Indian J Comp Microbiol Immunol Infec Dis. 1994;15(1-2): 42.

10. Shome BR, Songer JG, Shakuntala I, Shome R, Kumar A, Chakraborty S, et al. Atypical blackleg caused by Clostridium perfringens type A in cattle in Manipur, India. Indian J Anim Sci. 2006;76(5):353-7.

11. Niilo L. Toxigenic characteristics of Clostridium perfringens type $\mathrm{C}$ in enterotoxemia of domestic animals. Can J Vet Res. 1987;51(1):224-8.

12. Kumar A, Shakuntala L, Devi B. Prevalence of $\beta_{2}$ toxigenic Clostridium perfringens in poultry. Indian Vet J, 2011;88(1):52-3. 